\title{
Post PCI with stenting Follow-Up in Women for 7 Years in Public Sector Tertiary Care Cardiac Unit. Retrospective Study.
}

\author{
Khalida Soomro $^{1^{*}}$, Zaman baloch ${ }^{2}$ \\ ${ }^{1}$ Department of Cardiology, Dow University of Health and \\ Sciences Karachi, Pakistan. \\ ${ }^{2}$ Assistant prof of cardiology indus medical college Tando \\ mohammad khan pakistan.
}

\author{
*Corresponding author \\ Khalida Soomro, Department of Cardiology, Dow University of Health \\ and Sciences Karachi, Pakistan \\ Submitted: 08 Jun 2020; Accepted: 18 Jun 2019; Published: 16 July 2020
}

\begin{abstract}
Introduction: Despite of the fact that there is continual improvement in diagnostic and therapeutic procedures in catherization Lab introduction of better catheter techniques and new-generation stents and with the acquisition of knowledge from largescale clinical trials Still women appear to have a higher in-hospital mortality after PCI with stenting and during long term follow up specially in developing countries of South Asia the, Reason could be multi-factorial in women.
\end{abstract}

The objectives: The goals of treatment in PCI with stenting in Women is to improve quality of life, to prevent CHD from becoming symptomatic, prevent myocardial infarction, cardiac death and heart failure, the approaches to achieve these goals at the societal or individual level in this regards differ among various countries, the data that have been published are often limited due to the relatively small number of western women. It is important to collect data in under developed countries on outcomes of long term follow up of women with AMI after PCI with stenting to change the global perception of treatment of women with myocardial infarction.

\begin{abstract}
Material and Method: Out of 3300 patients, underwent successful PCI with stenting during 2010 to 2016 in Cath Lab of cardiology department of Dow University of Health and Sciences Karachi Pakistan , 577 patients with Sciences Karachi Pakistan, 577 patients with Myocardial infarction within 7 days were included in study and they constitute the present followup population. Additional data regarding noncardiac comorbid diseases and Risk factors were obtained along with crucial aspects of women's health, such as menopausal status, use of hormonal contraceptives, Follow-up was planned after 1 month and then with annualy for 7 years. The primary end point of study were the long-term rate of major adverse cardiac events (i.e. death, Infarction, and repeat revascularization). The secondary end points were the individual components of the major adverse cardiac events and stent thrombosis.
\end{abstract}

Result: This observational study was conducted by reviewing the record of cases performed and getting information on follow up visits of patients for 7 years from June 2010 to June 2016, out of total 3300 procedure 577 patients were included in the study who underwent PCI with stenting with in the 7 day of Myocardial infarction consisting of 346 patient from urban and 237 people from Rural areas of Sindh Balochistan Provinice of Pakistan Revascularization with stenting was performed in 313 patients 40-50 years of age followed by 219 patients 56-70 years of age in comparison to 23 in older group $>70$ years and 22 in younger age < 40 years, In 528 (91.5\%)patients PCI with BMS, in 28 (4.8\%)patients DES alone and in 21 (3.6\%)patients with BMS and DES performed The odds of short-term mortality were significantly higher among older postmenopausal group compared to premenopausal patients $<55$. I3 patients (5 patients during hospitalization) and 8 patients died within 30 days after PCI. Total 57((9.8\%) patient died during7 years follow up, 31 (58.5\%) cases due to comorbid conditions, and remaining 27 patients death was due to myocardial infarction in 13 (39.4\%). Arrhythmias in 5 (9.4\%) and worsening of heart Failure in 8 (42.1\%) elderly patients. Patient had complete Closure of Target Vessel, 28 (4.8\%) had Re PCI on 7 years follow up and CABG was performed in 13 (2.2\%). Patients main reason could be noncompliance of therapy in $71(12.3 \%)$ in patients.

Conclusion: Ideally a Women patient who has undergone coronary stent implantation should be cared for by the primary cardiologist who by working closely together for long term outcomes in different developing countries of South Asia to collect the data which will change the perception about the treatment of Myocardial infarction in women globally and help in making guidelines.

Keywords: PCI: Percutaneous Coronary Intervention, BMS: Bare Metal Stent, DES: Drug-Eluting Stent, CABG: Coronary Artery Bypass Grafting, MI: Myocardial Infarction, DM: Diabetes, HTN: Hypertension, CVD: Cardiovascular disease 


\section{Introduction}

Prior studies have suggested that women are at higher risk for morbidity and mortality during coronary angioplasty, although their long-term prognosis is similar after successful procedures [1]. Their higher mortality during procedure can be accounted for by their poorer clinical characteristics largely explained by their older age, comorbid conditions, and worse clinical status at the time of treatment more likely to present with atypical symptoms, delays in the administration of treatment, therefore have longer ischaemic period, leading to higher risk for mortality during procedure but not for similar long term prognosis, as women's of South Asian developing countries are less likely to receive evidence-based treatments during the procedure and Later on as secondary prevention in comparison to western women $[2,3]$. Data that have been published are often limited in developing countries due to the relatively small number of female patients included and have generally been limited to comparisons between men and women [4]. It is important to carefully document the long-term outcome of women undergoing this procedure in developing countries of South Asia like Pakistan.

\section{Objectives}

Although the causes of CVD in women are common to all parts of the world, the approaches to its secondary prevention at the societal or individual level differs among countries for cultural, social, medical, and economic reasons [4,5]. Whether we are achieving target goals of Coronary angioplasty in women which are to improve quality of life, to prevent $\mathrm{CHD}$ from becoming symptomatic due to heart failure and angina, in particular to prevent Myocardial infarction and cardiac death due to restenosis on follow up, the achievement of these goals requires a combination of drug treatment for secondary prevention, lifestyle changes, and reduction of cardiovascular risk factors. Low socioeconomical conditions and less awareness of women for CVD status have impact on the goals of coronary angioplasty in this part of world $[6,7]$. This article is concerned only with the follow-up data of patients who have undergone interventional therapy (coronary stent implantation) to change the perception of the treatment of women with CVD, who are too often under-diagnosed and under-treated hence less included in the research studies then the women of western countries to develop a global position statement including immediate procedural success as well as early and late outcomes [8-11].

\section{Materials and Methods}

The Base line features of a database includes demographic, clinical and procedural outcome details of 578 (25.4) women patients from total procedures 3378 (74.6\%) who had undergone successful stenting in native arteries treated with PCI within 7 days of myocardial infarction in Cath Lab of Cardiology Department of Dow university of Health and Sciences Karachi Pakistan from March 2010 to March 2016 were identified and assessed retrospectively to evaluate 7 years out comes. Patients with a prior PCI or CABG were excluded for accurate identification of those who required any repeat revascularization. The following clinical covariates were included in the adjusted model: age, smoking status, history of Diabetes mellites, Hypertension, Dyslipidaemia, Cerebrovascular disease, Congestive heart disease, (Left ventricular ejection fraction), peripheral vascular disease, Pulmonary and liver disease Malignancy, Dialysis, as well as peri-procedural variables, procedure urgency, disease severity (3-vessel or left main vs. rest) and to evaluate crucial women's health such as menopausal status. Use of hormonal contraceptives. Patients were followed up regularly on one month, (every three to six months) for one year and on yearly basis for 7 years. Follow up of all patients dismissed from the hospital was maintained in outdoor patients department on card for visits or obtained by an experienced data technician by telephone 6 and 12 months after the initial procedure and continued annually thereafter up to 7 years yearly if they were unable to come for visit due to long distance. In follow up visits clinical history taking on secondary stabilization, which was defined as freedom from recurrence of angina, compliance of drugs if patient was not achieving adequate symptomatic relief, h/o Myocardial infarction, coronary artery bypass grafting, and use of target lesion-percutaneous coronary intervention (TL-PCI) and death was sought. All Patients were grouped as follows: $<40.40-54$ years, 55-69 years ad $\geq 70$ years old, and PCI with stent placement were assessed accordingly (BMS or DES). Survival probabilities in one month, one year and 2 year, 5year and7years were estimated by using the Kaplan-Meier method. Cox hazards regression models were used to Test results with a p-value $<0.05$ where needed. The primary end point of study was the long-term rate of major adverse cardiac events (i.e., death, Infarction, and repeat revascularization). The secondary end points were the individual components of the major adverse cardiac events and stent thrombosis.

\section{Results}

Baseline characteristics and the indications for coronary stenting were similar in women of all ages, Amongst 3300 revascularized patients 577 (25.4\%) women who underwent native coronary arteries revascularization 7days of AMI were included in this study, $347(60.1 \%)$ from urban and 289 (35.2\%) from rural areas of Sindh and Baluchistan province of Pakistan. PCI with stenting perfomed along with antiplatelet drug of the glycoprotein 11b/111a inhibitors class Tirofiban or eptifibatide or fractionated heparin in 363(62.9\%). 97(19.9\%) and 119 (19.9\%) respectively.

\begin{tabular}{|l|l|l|}
\hline Area of living; $\mathrm{n}(\mathrm{n} \%)$ & $\begin{array}{l}\text { Urban } \\
\text { Rural }\end{array}$ & $\begin{array}{l}347(60.1) \\
230(39.9)\end{array}$ \\
\hline Age; mean \pm SD & Age & $54.84 \pm 9.56$ \\
\hline Medication; $\mathrm{n}(\mathrm{n} \%)$ & Tirofiban & $363(62.9)$ \\
\cline { 2 - 3 } & Clexane & $97(16.8)$ \\
\cline { 2 - 3 } & Eptifibatide & $115(19.9)$ \\
\hline \multirow{2}{*}{ EF; n (n\%) } & $\begin{array}{l}<35 \% \text { (Severely } \\
\text { below Normal) }\end{array}$ & $25(4.3)$ \\
\cline { 2 - 3 } & $\begin{array}{l}35 \% \text { to 39\% (Moder- } \\
\text { ately below Normal) }\end{array}$ & $64(11.1)$ \\
\cline { 2 - 3 } & $\begin{array}{l}40 \% \text { to 54\% (Slightly } \\
\text { below Normal) }\end{array}$ & $429(74.4)$ \\
\cline { 2 - 3 } & 55\% to 70\% (Normal) & $59(10.2)$ \\
\cline { 2 - 3 } & & \\
\hline
\end{tabular}

Table 1: Demographics and other study characteristics (Total Patients $=577)$ On 2D Echocardiography assessment $429(74.4 \%)$ pa- 
tients of $<54$ years of age had mild LV dysfunction then 64 (11.1\%) patients had moderate LV dysfunction and 25((4.35\%) with Sever LV dysfunction mostly in older women with co morbid conditions (Table 1), Revascularization with stenting was performed in 313 patients of age group 40-5o years followed by 219 patients in age group of 56-70 years in comparison to 23 in older group $>70$ years and 22 in younger age $<40$ years.

\begin{tabular}{|l|l|}
\hline Age & Total No $\mathbf{P C I}(\mathbf{n}=\mathbf{5 7 7})$ \\
\hline Less than 40 & 22 \\
\hline $40-55$ years & 313 \\
\hline $56-70$ years & 219 \\
\hline Above 70 years & 23 \\
\hline
\end{tabular}

Table 2: Revascularization ratio in different age groups. (Total No of Patients 577)

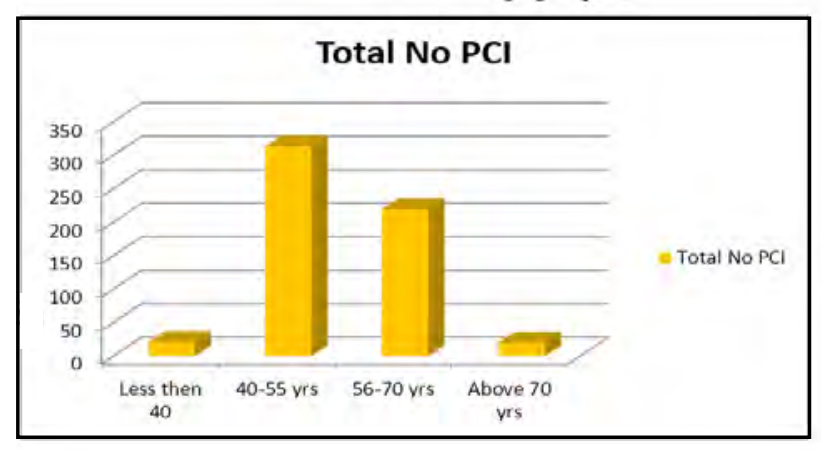

In $528(91.5 \%)$ patients PCI with BMS, in 28 (4.8\%) patients DES alone and in $21(3.6 \%)$ patients with BMS and DES performed (Table 3).

Table 3: Revascularisation with DES AND BMS

\begin{tabular}{|l|l|}
\hline Type of stent PCI. & Total number of Patients .577 \\
\hline DES stent & $28(4.8 \%)$ \\
\hline BMS stent & $528(91.5 \%)$ \\
\hline DES AND BMS & $21(3.6 \%)$ \\
\hline
\end{tabular}

Table 3: Types of Stent used during revascularization

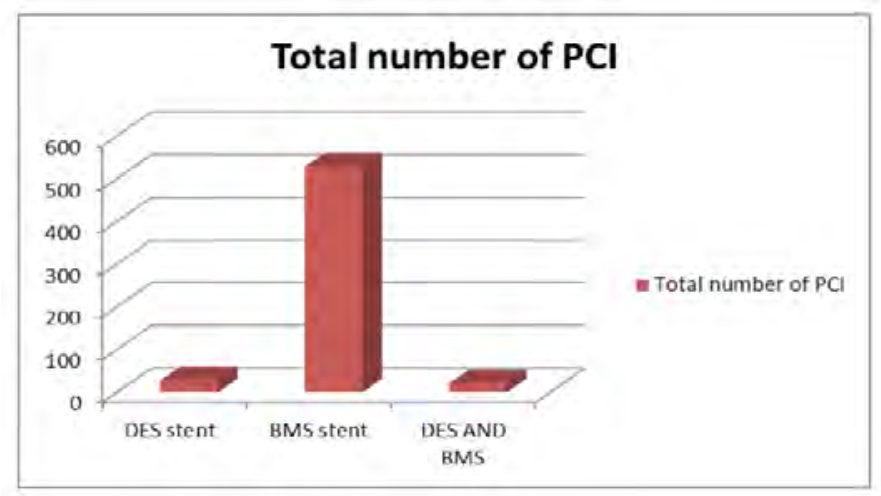

Differences in outcomes have been observed and may be explained by Vessels involved and higher prevalence of risk factors diabetes mellitus in $38(15.1 \% \mathrm{P}<0.001)$. Hypertension in $138(41.3 \%$ $\mathrm{P}=0.006$ ) in older age group (55-69years ) and high modifiable risk factors such as smoking in 7(3.2\%), tobacco use in 33(9.9\%), obesity in $19(5.7 \%)$ and oral contraceptives in $15(4.2 \%)$ younger patients of age group $<54$ years. (Table 4 ).

Table 4: Risk factors distribution among age groups.

\begin{tabular}{|l|l|l|}
\hline \multirow{2}{*}{ Risk factors } & $(\mathrm{n}=577)$ & \\
\cline { 2 - 3 } & $\begin{array}{l}<55 \text { years } \\
\mathrm{n}(\mathrm{n} \%)\end{array}$ & $\begin{array}{l}55 \text { \& above years } \\
\mathrm{n}(\mathrm{n} \%)\end{array}$ \\
\hline $\begin{array}{l}\text { Hypertension } \\
\text { (HTN) }\end{array}$ & $99(41.6 \%)$ & $138(41.3 \%)$ \\
\hline $\begin{array}{l}\text { Diabetes Mellitus } \\
\text { (DM) }\end{array}$ & $37(11.1 \%)$ & $36(15.1 \%)$ \\
\hline HTN and DM & $73(23.4 \%)$ & $78(30,7 \%)$ \\
\hline Dyslipidemia & $7(2.1 \%)$ & $6(2.5 \%)$ \\
\hline Obesity & $19(5.7 \%)$ & $6(2.5 \%)$ \\
\hline Smoking & $7(2.1 \%)$ & $2(0.8 \%)$ \\
\hline $\begin{array}{l}\text { Use of hormonal } \\
\text { contraceptives }\end{array}$ & $15(4.5 \%)$ & - \\
\hline Oral tobacco users & $33(9.9 \%)$ & $16(6.7 \%)$ \\
\hline Total & $334(57.9 \%)$ & $243(42.1 \%)$ \\
\hline
\end{tabular}

\begin{tabular}{|l|l|l|}
\hline Risk Factors & Pre-menopausal & Post-menopausal \\
\hline Age & $<55$ years & $>55$ years \\
\hline DM & $35(10.1 \%)$ & $38(15.1 \%)$ \\
\hline HTN & $99(41.3 \%)$ & $138(41.3 \%)$ \\
\hline DM, HTN & $70(28.8 \%)$ & $78(33.2 \%)$ \\
\hline Dyslipidemia & $7(0.2 \%)$ & $5(2.0)$ \\
\hline DM, Dyslipidemia & $30(8.8)$ & $32(13.2)$ \\
\hline HTN, Dyslipidemia & $2(0.5)$ & $3(1.2)$ \\
\hline obesity & $19(5.7 \%)$ & $6(2.5 \%)$ \\
\hline obesity DM & $1(0.2 \%)$ & - \\
\hline $\begin{array}{l}\text { HTN, Tobacco, } \\
\text { Obesity }\end{array}$ & $1(0.2 \%)$ & $1(0.4 \%)$ \\
\hline Smoker & & $2(1.2 \%)$ \\
\hline Oral contraceptive & $15(4.2 \%)$ & - \\
\hline Oral Tobacco & $33(9.9 \%) 33(9.9 \%)$ & $16(6.6 \%)$ \\
\hline DM, Tobacco & $2(1,2 \%)$ & - \\
\hline HTN. Tobacco & $3(1.2 \%)$ & $2(1.2 \%)$ \\
\hline HTN, Obesity & $3((1.8 \%)$ & $2(1.2 \%)$ \\
\hline HTN, DM, Obesity & $1(0.2 \%)$ & $1(.8 \%)$ \\
\hline
\end{tabular}

Table 4: Risk Factor Profile of Patients 


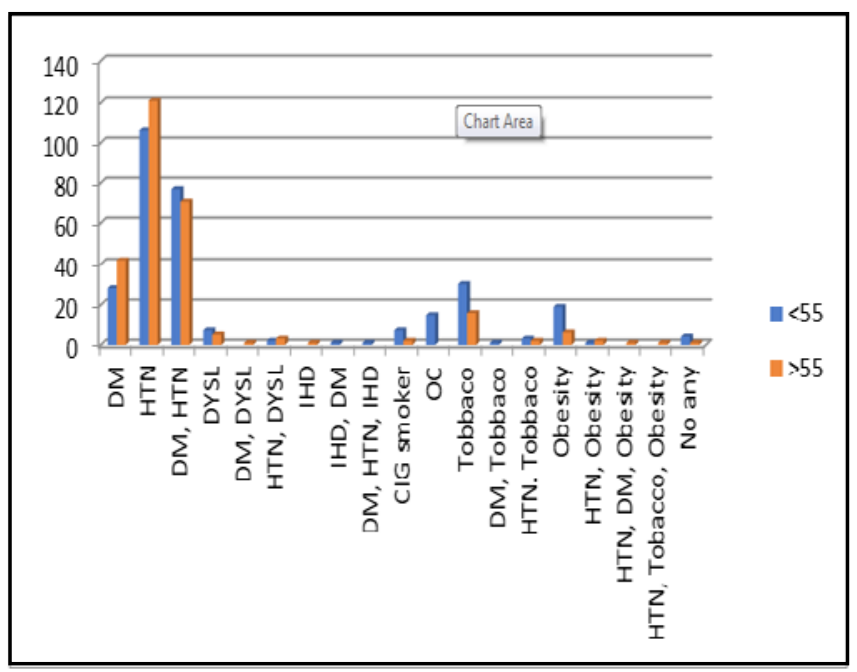

The more prevalence of 3-vessel coronary artery disease observed in $15(14.4 \%)$ out of 60 women of older age group $>70$ followed by $53(51.0 \%)$ out of 286 womens of 55-70 years age after controlling for baseline characteristics,

Table 5: Distribution of number of vessels diseases among age groups ( $\mathrm{n}=577)$

\begin{tabular}{|l|l|l|l|l|}
\hline Age groups & Total & SVD & 2VD & 3VD \\
\hline $30-54$ years & $231(40.0)$ & $110(43.3 \%)$ & $85(38.8 \%)$ & $36(34.6 \%)$ \\
\hline $55-69$ years & $286(49.6 \%)$ & $119(46.9 \%)$ & $114(52.1 \%)$ & $53(51.0 \%)$ \\
\hline$>70$ years & $60(10.4)$ & $25(9.8 \%)$ & $20(9.1 \%)$ & $15(14.4 \%)$ \\
& & & & \\
\hline
\end{tabular}

The odds of short-term mortality were significantly higher among older age group and post-menopausal compared to premenopausal patients $<55$. I3 patients (5 patients during hospitalization) and 8 patients died within 30 days after PCI.

Table 6: Mortality $(n=53)$

\begin{tabular}{|l|l|}
\hline Within 1 month & $13(2.2 \%)$ \\
\hline Within 1years & $18(3.1 \%)$ \\
\hline Within 2year & $9(1.5 \%)$ \\
\hline Within 5years & $13(2.3 \%)$ \\
\hline Within 7years & $4 .((.8 \%)$ \\
\hline Total & $57(9.8 \%)$ \\
\hline
\end{tabular}

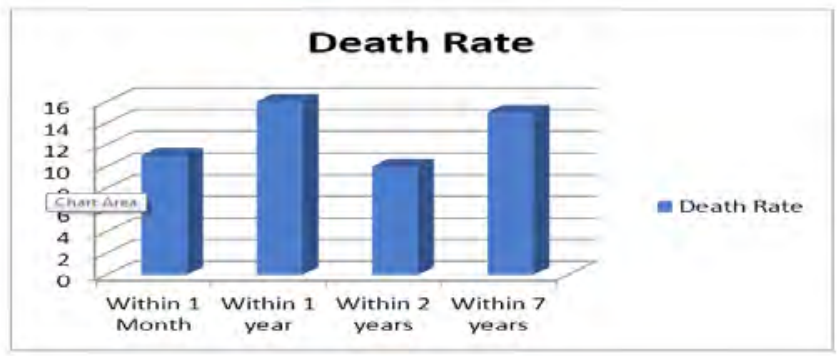

Table 7: Conditions underlying cause for death $(n=57)$

\begin{tabular}{|l|l|}
\hline Cause of Death & $\mathbf{n}(\mathbf{n} \%)$ \\
\hline Comorbid conditions & $31(58.5)$ \\
\hline ACS (MI) & $13(39.4)$ \\
\hline Arrhythmias & $5(9.4)$ \\
\hline Heart Failure & $8(42.1 \%)$ \\
\hline
\end{tabular}

During hospitalization sudden cardiac death occurred in 2 patients due to arrhythmias and in 3 patients with re - myocardial infarction with shock in first month after PCI. high mortality observed during 1st year after PCI , 18 patients in comparison to other years. Total 57((9.8\%) patient died during7 years follow up , 31 (58.5\%) cases due to comorbid conditions like cerebrovascular accidents, Peripheral arterial diseases, Renal failure. Cirrhosis of liver. lung disease and breast cancer, in remaining 27 patients death was due to myocardial infarction in 13 ((39.4\%). Arrhythmias in 5(9.4\%) and worsening of heart Failure in $8(42.1 \%)$ elderly patients. Restenosis rates were high in 5th years of follow up out of 17 patient 11 patient had Successful Re PCI PCI. While in 7 years follow up 13 patients more had restenosis out of those 10 cases had successful Re- PCI with stenting and 7 patients under went CABG in 5th year of follow up. 15 (2.5\%) patient had complete Closure of Target Vessel 28 (4.8\%)had Re PCI on 7 years follow up and CABG was performed in 13 (2.2\%) patients main reason could be noncompliance of therapy in $71(12,3 \%)$ in patients.

Table 8: Noncompliance of drugs and coronary events.

\begin{tabular}{|l|l|l|l|l|}
\hline Duration & NOC & $\begin{array}{l}\text { Closed } \\
\text { STENT }\end{array}$ & RE PCI & CABG \\
\hline 1 Month & 8 & 1 & 2 & 0 \\
\hline 1 Year & 19 & 3 & 4 & 3 \\
\hline 2 Year & 14 & 1 & 1 & 1 \\
\hline 5 Year & 22 & 7 & 11 & 7 \\
\hline 7 Year & 8 & 3 & 10 & 2 \\
\hline Total & $71(12.3 \%)$ & $15(2.5 \%)$ & $28(4.8 \%)$ & $13(2.2 \%)$ \\
\hline
\end{tabular}


In the adjusted analyses, the risk of recurrent AMI leading to Re -PCI, there was no significant difference in the use of further angioplasty procedures between women of premenopausal and post-menopausal. Urban and rural women. Except non follow up mainly in rural area patients.

Table 9: Survival and death percentage of women in different follow-up periods $(\mathrm{n}=577)$

\begin{tabular}{|l|l|l|l|}
\hline $\begin{array}{l}\text { Follow-up } \\
\text { Duration }\end{array}$ & $\begin{array}{l}\text { Death } \\
\mathrm{n}(\mathrm{n} \%)\end{array}$ & $\begin{array}{l}\text { Follow-up } \\
\mathrm{n}(\mathrm{n} \%)\end{array}$ & $\begin{array}{l}\text { Non-Follow- } \\
\text { up } \\
\mathrm{n}(\mathrm{n} \%)\end{array}$ \\
\hline$<1$ month & $13(2.2 \%)$ & $555(96.1 \%)$ & $19(3.2 \%)$ \\
\hline$<1$ year & $18(3.1 \%)$ & $514(89 \%)$ & $25(4.5 \%)$ \\
\hline$<2$ years & $9(1.5 \%)$ & $489(84.7 \%)$ & $6 .(1.1 \%)$ \\
\hline$<5$ years & $13(2.3 \%)$ & $469(81.2 \%)$ & $7(1.4 \%)$ \\
\hline$<7$ years & $4 .(.8 \%)$ & $459(79.5 \%)$ & $6(1.2 \%)$ \\
\hline Total & $57(9.8)$ & $459(79.5 \%)$ & $65(11.2 \%)$ \\
\hline
\end{tabular}

Compares survival and death in women, shows out of 577 the probability of survival was in $459(79.5 \%)$ patients who were in follow up for 7 years and Death occurred in 57 patients (11.2\%) more in elderly patients. 65 (11.2\%) not followed the visits. over all women of age $>70$ had slightly lower survival than women of young age. The Probability of survival at 7years was $73 \%$ in premenopausal women versus $78 \%$ post-menopausal $(\mathrm{P}=.06)$ after adjustment for important baseline variables, and there was no significant survival difference between women of two classes (relative mortality risk, 0.94 ; CI, 0.76 to 1.15. except comorbid condition and type of stent used death was more observed in Patients with BMS then DES.

Table 10: Mortality rate among stent type and follow-up duration $(\mathrm{n}=53)$

\section{Type of stent}

\begin{tabular}{|l|l|l|l|}
\hline $\begin{array}{l}\text { Follow up } \\
\text { duration }\end{array}$ & $\begin{array}{l}\text { PCI with } \\
\text { BMS stent } \\
\mathrm{n}(\mathrm{n} \%)\end{array}$ & $\begin{array}{l}\text { PCI with DES } \\
\text { stent } \\
\mathrm{n}(\mathrm{n} \%)\end{array}$ & $\begin{array}{l}\text { PCI with DES } \\
\text { and BMS } \\
\mathrm{n}(\mathrm{n} \%)\end{array}$ \\
\hline Up to 1 month & $10(30.3 \%)$ & $1(5.3 \%)$ & - \\
\hline$<1$ year & $2(6.1 \%)$ & $1(5.3 \%)$ & - \\
\hline$<2$ year & $13(39.4 \%)$ & $8(42.1 \%)$ & - \\
\hline$<5$ years & $5(15.2 \%)$ & $7(36.8 \%)$ & - \\
\hline$<7$ years & $2(6.1 \%)$ & $1(5.3 \%)$ & $1(100.0 \%)$ \\
\hline $\begin{array}{l}7 \text { years and } \\
\text { above }\end{array}$ & $5(15.2 \%)$ & $1(5.3 \%)$ & - \\
\hline Overall death & $37(65.3 \%)$ & $19(35.8 \%)$ & $1(1.9)$ \\
\hline
\end{tabular}

\section{Discussion}

There is evidence to suggest that women with Myocardial infarction are less likely to receive evidence-based treatments and less likely to undergo revascularisation Worldwide $[12,13]$. In this observational study we found, out of 3300 performed PCI only 577 (17.4\%) women underwent revascularization with stenting, this correlates with a large French registry of 74,389 consecutive patients (30\% women) demonstrated a lower rate of PCI with stenting in women having an acute MI $(14.2 \%$ versus $24.4 \%$; $<<0.001)$. In the same study, in-hospital mortality was significantly higher in women ( $14.8 \%$ versus $6.1 \%$; $\mathrm{p}<0.0001)$. in hospital mortality after PCI was slightly higher $5(8.7 \%)$ patients vs 57 patients in 7 years. Urban women underwent more PCI then the rural women (347(60.1\%) VS 230 (30.9\%) due to long distance and logistic problems.

In this observational study we found worse prognosis in older women specially $>55$ with AMI following revascularization compared to premenopausal women $<55$ years of age .Observed differences in death, risk of recurrent MI, RE-PCI and heart failure were due to co morbid conditions, severity of coronary Disease, type of stent used and no compliance of drugs due to Lack of awareness about the Problem in women and low socio-economic status, Our findings of non-significant short-term mortality 13 (2.2\%) patients in1st month following PCI correlates with to a recent study finding where the rates of short term all-cause and cardiac mortality following PCI were lower in Asian patients (Singapore, Hong Kong, and Malaysia) compared to their counterparts from Western Europe [14]. This correlation is may be due to the fact that our population of AMI is compared to a lower risk unselected coronary disease population in the study above. Moreover, we directly compared outcomes in women's within a single health care system despite the fact that we included the women of the rural area who may have had arrived later to the emergency department resulting in less effectiveness of the procedures or more extensive myocardial damage at time of PCI. But in our study use of glyco protein $11 \mathrm{~b} / 111 \mathrm{a}$ inhibitors and direct thrombin inhibitors, prior to PCI in majority of patients lead to less significant short-term mortality However, in our study, we extensively adjusted for differences in baseline prognostic characteristics and extent of coronary disease. while no significant difference between two populations was observed for mortality, except older age group which was found to have comparatively at increased risk of -fatal adverse cardiovascular events following PCI compared to younger age group premenopausal and non-significant difference in non-fatal events specially, While several studies of unselected coronary disease patients have revealed no difference in fatal cardiac outcomes in South Asian and White patients in a study following PCI, during the 2 years after the initial procedure or after the last TL-PCI, was achieved in 373 patients (92\%) overall. Only 6 patients $(1.7 \%)$ underwent TL-PCI [15]. After the initial 12 years period, 20 women underwent repeat cardiac catheterization, revealing similar rates of restenosis, in 91 patients at 7 years similarly, the annual incidence of stent thrombosis was less than $1 \%$, but as many as $80 \%$ of persons with stent 
thrombosis had myocardial infarction, and as many as half of these persons died. Where as in our study Total $57((9.8 \%)$ patient died, $31(58.5 \%)$ cases died due to comorbid conditions, in rest of 27 patients death was due to myocardial infarction in 13 (39.4\%). Arrhythmias in 5(9.4\%) and worsening of heart Failure in $8(42,1 \%)$ cases. restenosis observed in 17 patients at 5 years of follow up, out of these patients 11 patient had successful PCI. while up to 7 years follow up 13 more patients had restenosis and amongst them 10 cases had successful revascularization, symptomatic improvement was much better in younger age group women after successful coronary angioplasty. In 7 years follow up total 15 (2.5\%) patient had complete Closure of Target Vessel, 28 (4.8\%) had Re PCI and CABG was performed in 13 (2.2\%) patients (TABLE 7) main reason could be noncompliance of therapy in $71(12.3 \%)$ in patients and the tendency to underestimate the problem by women themselves due to lack of awareness and they have roles to play in maximizing adherence to optimal primary and secondary prevention measures. To decrease the risk of RePCI and CABG with the latest drug coated stents, the numbers of stent thrombosis and rePCI and CABG can be even more lower [16-21]. Recently published data demonstrates the safety and efficacy of the use of contemporary DES in 2,176 women after acute MI [22]. In our study due to low socio economical condition of the patient and in a tertiary care public sector set up DES was less used in Study and that had insignificant impact on primary end points and on survival of patients as most patient had bare metal stents specially in diabetic women.

Our study represents a direct comparison of women of rural and urban population with varying age according to premenopausal and menopausal age suffering from of AMI patients in a single health care system using extensive adjustment for prognostic factors including severity of coronary disease. However, several study limitations should be noted. First, this study is an observational study and the ideal study design for determining efficacy of these procedures following AMI would be a randomized trial. This study is thus susceptible to treatment-selection bias although we did adjust for multiple potential confounding factors, we were not able to control for risk behaviours, dyslipidaemia or extent of infarct (nonST elevation MI, or peak cardiac enzyme level) that could explain the observed difference in outcomes.

\section{Conclusion}

Evaluation in the use of PCI for the management of coronary artery disease have been shared commonalities of the disease process globally in women's by their unique pathologic process and responses to interventions and therapeutics, despite their greater baseline risk profile, women are significantly less likely to have received effective treatment, the use of including drug-eluting stents and use of glycol protein $11 \mathrm{~b} / 111 \mathrm{a}$ inhibitors and direct thrombin inhibitors, these behind-the scenes risk factors, plays a role that add up to a higher mortality risk on follow up women after PCI due to the numerous bearer to heart health in women chief among mainly due to socio economic reasons non-compliance to drugs and non-adherence to follow up. Which are not taken care of in this part of the world [23].
This study found Observed socioeconomical and age related disparities in outcomes which were present despite adjustment for demographic, and clinical characteristics. We believe the presence of awareness programs for the importance of adherence to secondary prevention medication, and timely seek of care, along with equitable access to health care, may help further reginal disparities in post revascularization outcomes.

\section{References}

1. Jafary FH, Ahmed H, Kiani J (2007) Outcomes of primary percutaneous coronary Intervention at a joint commission international accredited hospital in a developing country- can good results, possibly similar to the west, be achieved? J Invas Cardiol 19: 417-423.

2. Quan H, Khan N, Li B, Humphries KH, Faris P, et al. (2010) Invasive cardiac procedure use and mortality among South Asian and Chinese Canadians with coronary artery disease. Can J Cardiol 26: e236-e242.

3. Khan M S, Jafary F H, Faruqui A M, Rasool SI, Hatcher J, et al. (2007) High prevalence of lack of knowledge of symptoms of acute myocardial infarction in Pakistan and its contribution to delayed presentation to the hospital. BMC Public Health 7: 284.

4. Shaikh AH, Siddiqui MS, Hanif B, Malik F, Hasan K, et al. (2009) Outcomes of Primary Percutaneous Coronary Intervention in a Tertiary Care Cardiac Centre. J Pak Med Assoc 59: 426-429.

5. Khan M S, Jafary FH, Jafar TH, Fauqui AM, Rasool SI, et al. (2006) Knowledge of modifiable risk factors of heart disease among patients with acute myocardial infarction in Karachi, Pakistan: A cross sectional study. BMC Cardiovasc Disord 6: 18.

6. Pinto DS, Kirtane AJ, Nallamothu BK, Murphy SA, Cohen DJ, et al. (2006) Hospital delays in reperfusion for ST-elevation myocardial infarction: implications when selecting a reperfusion strategy. Circulation 114: 2019-2025.

7. Cannon GP, Gibson GM, Lambrew CT, Shoultz DA, Levy D, et al. (2000) Relationship of symptom-onset-to-balloon time and door to balloon time with mortality in patients undergoing angioplasty for acute myocardial infarction. JAMA 283: 2941-2947.

8. Kushner F G, Hand M, Smith S C, King SB, Anderson JL, et al. (2009) 2009 Focused updates: ACC/AHA Guidelines for the management of patients with ST-elevation myocardial infarction (updating the 2004 Guideline and 2007 focused update) and ACC/AHA/SCAI Guidelines on Percutaneous Coronary Intervention (updating the 2005 Guideline and 2007 focused update). Cath Cardiovasc Interv 74: E25-E68.

9. Weintraub WS, Grau-Sepulveda MV, Weiss JM, Sean M O'Brien, Eric D Peterson, et al. (2012) Comparative effectiveness of revascularization strategies. N Engl J Med 366: 14671476.

10. Levine GN, Bates ER, Blankenship JC, Bailey SR, Bittl JA, et al. (2011) 2011 ACCF/AHA/ SCAI Guideline for Percutaneous Coronary Intervention: A Report of the American College of Cardiology Foundation/American Heart Association 
Task Force on Practice Guidelines and the Society for Cardiovascular Angiography and Interventions. Circulation 124: e574-e651.

11. Gasevic D, Khan NA, Qian H, Karim S, Simkus G, et al. (2013) Outcomes following percutaneous coronary intervention and coronary artery bypass grafting surgery in Chinese, South Asian and White patients with acute myocardial infarction: administrative data analysis. BMC Cardiovasc Disord 13: 121.

12. Toor IS, Jaumdally R, Lip GYH, Pagano D, Dimitri W, et al. (2011) Differences between South Asians and White Europeans in five year outcome following percutaneous coronary intervention. Int J Clin Pract 65: 1259-1266.

13. Jones DA, Gallagher S, Rathod KS, Redwood S, de Belder MA, et al. (2014) Mortality in South Asians and Caucasians after percutaneous coronary intervention in the United Kingdom: an observational cohort study of 279,256 patients from the BCIS (British Cardiovascular Intervention Society) National Database. JACC Cardiovasc Interv 7: 362-371.

14. Scanlon PJ, Faxon DP, Audet AM, Blase Carabello, Dehmer GJ, et al (1999) ACC/AHA guidelines for coronary angiography: executive summary and recommendations. A report of the American College of Cardiology/American Heart Association Task Force on Practice Guidelines (Committee on Coronary Angiography) developed in collaboration with the Society for Cardiac Angiography and Interventions. Circulation 99: 2345-2357.

15. Hamm CW, Bassand JP, Agewall S, Jeroen Bax, Eric Boersma, et al. (2011) ESC Guidelines for the management of acute coronary syndromes in patients presenting without persistent ST-segment elevation: The Task Force for the management of acute coronary syndromes (ACS) in patients pre-senting without persistent ST-segment elevation of the European Society of Cardiology (ESC). Eur Heart J 32: 2999-3054.

16. Meadows TA, Bhatt DL, Cannon CP, Gersh BJ, Rother J, et al.
(2011) Ethnic differences in cardiovascular risks and mortality in atherothrombotic disease: insights from the Reduction of Atherothrombosis for Continued Health (REACH) registry. Mayo Clin Proc 86: 960-967.

17. Kirtane AJ, Gupta A, Iyengar S, Moses JW, Leon MB, et al. (2009) Safety and efficacy of drug-eluting and bare metal stents: comprehensive meta-analysis of randomized trials and observational studies. Circulation 119: 3198-3206.

18. Stolker JM, Kennedy KF, Lindsey JB, Marso SP, Pencina MJ, et al. (2010) Predicting restenosis of drug-eluting stents placed in real-world clinical practice: derivation and validation of a risk model from the EVENT registry. Circ Cardiovasc Interv 3: 327-334.

19. Mishkel GJ, Moore AL, Markwell S, Shelton MC, Shelton ME, et al. (2007) Long-term outcomes after management of restenosis or thrombosis of drug-eluting stents. J Am Coll Cardiol 49: 181-184.

20. Chen MS, John JM, Chew DP, Lee DS, Ellis SG, et al. (2006) Bare metal stent restenosis is not a benign clinical entity. Am Heart J 151: 1260-1264.

21. Brister SJ, Hamdulay Z, Verma S, Maganti M, Buchanan MR (2007) Ethnic diversity: South Asian ethnicity is associated with increased coronary artery bypass grafting mortality. J Thorac Cardiovasc Surg 133: 150-154.

22. Hadjinikolaou L, Klimatsidas M, Maria Iacona G, Spyt T, Samani NJ (2010) Short-and medium-term survival following coronary artery bypass surgery in British Indo-Asian and white Caucasian individuals: impact of diabetes mellitus. Interact Cardiovasc Thorac Surg 10: 389-393.

23. Mangiapane S, Busse R (2011) Prescription prevalence and continuing medication use for secondary prevention after myocardial infarction: the reality of care revealed by claims data analysis. Dtsch Arztebl Int 108: 856-862.
Copyright:@2020 Khalida Soomro.,This is an open-access article distributed under the terms of the Creative Commons Attribution License, which permits unrestricted use, distribution, and reproduction in any medium, provided the original author and source are credited. 